\section{Estimating Daily Water Use of Two Petunia Cultivars Based on Plant and Environmental Factors}

\author{
Jongyun Kim ${ }^{1}$ and Marc W. van Iersel \\ Department of Horticulture, University of Georgia, 1111 Miller Plant Science \\ Building, Athens, GA 30602 \\ Stephanie E. Burnett \\ Department of Plant, Soil, and Environmental Sciences, University of Maine, \\ 5722 Deering Hall, Orono, ME 04469
}

Additional index words. capacitance sensor, greenhouse irrigation, container size, daily light integral, vapor pressure deficit, modeling

\begin{abstract}
Many ornamental plant growers water excessively to reduce the risk of drought stress. Scheduling irrigation in greenhouses is challenging because there is little quantitative information about ornamental plant water requirements and how water use changes when plants are grown in varying greenhouse environmental conditions. Models to estimate the daily water use (DWU) of greenhouse crops may provide a useful tool to conserve irrigation water. Our objective was to develop a model to predict DWU based on plant age and easily acquirable environmental data. Two petunia (Petunia $\times$ hybrida) cultivars, Single Dreams Pink and Prostrate Easy Wave Pink, were grown in different sized containers (diameter $=10,12.5$, and $15 \mathrm{~cm}$ ) to quantify their DWU for 6 weeks. The substrate water content $(\theta, v / v)$ was maintained at $0.40 \mathrm{~m}^{3} \cdot \mathrm{m}^{-3}$ using an automated irrigation system with capacitance soil moisture sensors. Every irrigation event was recorded by a data logger, and this information was used to calculate the DWU of the plants. On overcast days early in the experiment, plants used only 4.8 to 13.8 $\mathrm{mL} \cdot \mathrm{d}^{-1}$. The maximum DWU of 'Single Dreams Pink' was 63, 96, and $109 \mathrm{~mL} \cdot \mathrm{d}^{-1}$ in 10-, 12.5-, and 15-cm containers, respectively. Late in the experiment, 'Prostrate Easy Wave Pink' petunia used more water than 'Single Dreams Pink' because of their more vigorous growth habit. DWU was modeled as a function of days after planting (DAP), daily light integral (DLI), vapor pressure deficit (VPD), temperature, container size, and interactions between these factors and DAP $\left(R^{2}=0.93\right.$ and 0.91 for 'Single Dreams Pink' and 'Prostrate Easy Wave Pink', respectively). Days after planting and container size were the most important factors affecting DWU and are indicative of plant size. Daily light integral was the most important environmental factor affecting DWU. These models, describing the DWU as a function of the DAP and environmental conditions, may be used as guidelines for accurately watering petunias in greenhouses and may improve irrigation scheduling.
\end{abstract}

As water scarcity increases worldwide, it has become critical to use water efficiently in agriculture. Climate change is predicted to alter precipitation patterns. Concurrently, use of water in urban centers will likely increase as a result of population growth (IPCC, 2007). These changes will likely increase water scarcity in the future. In much of the world, existing water supplies are insufficient to meet all of the urban, industrial, agricultural, and environmental demands. In particular, agricultural

Received for publication 6 May 2011. Accepted for publication 29 June 2011

Funding for this research was provided by USDANIFA-SCRI award no. 2009-51181-05768 and the Fred C. Gloeckner Foundation

We thank Fafard Inc. for donating the growing medium and C. Raker and Sons for donating plant material. We gratefully acknowledge Lisa Donavan, Anish Malladi, and Paul Thomas for helpful comments.

${ }^{1}$ To whom reprint requests should be addressed; e-mail jongyun@uga.edu. water use is often regarded as unsustainable for reasons including soil salinization (as the result of irrigation), groundwater overdraft, and the overallocation of available surface water supplies (IPCC, 2007; Jury and Vaux, 2005). Many states in the United States and countries in Europe are adopting restrictive laws to limit water wastage and pollution that will address these problems. These laws will force growers to seriously consider their irrigation control systems and strategy, and efficient irrigation will become more essential (Majsztrik et al., 2011).

Efficient irrigation practices are vital not only to conserve, but also because they affect plant quality in commercial greenhouse production. Growers commonly apply excess water to minimize drought-induced shrinkage. However, overwatering increases plants' vulnerability to diseases such as root rot (i.e., Fusarium, Pythium, Phytophtera, Rhizoctonia, and Thielaviopsis), which can lead to plant death or decreased quality (Nelson, 1998).
Excessive irrigation also leaches fertilizer, which constitutes an economic loss and can lead to environmental pollution. Previous research indicated that good water management practices can improve nutrient management (Bilderback, 2002; Million et al., 2007; Warsaw et al., 2009). Proper irrigation management in container plant production is more critical than for field-grown plants as a result of the limited substrate volume, which restricts water and nutrient availability. Efficient irrigation can reduce costs and increase profits by reducing leaching and runoff of fertilizer caused by excessive irrigation (Majsztrik et al., 2011; Million et al., 2007).

Previous studies reported that the use of appropriate irrigation systems and scheduling saves a significant amount of water while maintaining or increasing yield and product quality in horticultural production (Bacci et al., 2008; Beeson and Brooks, 2008; Blonquist et al., 2006; Fereres et al., 2003). Although many U.S. growers use efficient irrigation systems such as drip irrigation (41\%) or subirrigation (5\%), overhead irrigation still prevails $(63 \%)$ in greenhouse and nursery production of ornamental plants (Hodges et al., 2008). Soil moisture sensor-based automated irrigation allows for precise irrigation (Jones, 2004), and we have previously shown that this can effective in greenhouses (Burnett and van Iersel, 2008; Kim and van Iersel, 2009; Nemali and van Iersel, 2006; van Iersel et al., 2010). Combining sensors with crop water use models may further improve irrigation of ornamental plants in containers (Bacci et al., 2008). By integrating precise irrigation systems with proper irrigation scheduling, efficient irrigation management can be achieved, saving water, labor, electricity, and fertilizer.

Estimates of the required irrigation amount can be based on plant and environmental factors. Plant size affects water use because it affects plants' transpirational surface area (Ray and Sinclair, 1998). Environmental factors such as light, air humidity, air temperature, wind, and soil water availability also affect water use (Allen et al., 1998; Jones and Tardieu, 1998). Light is an important environmental factor affecting plant water use as a result of its effects on evaporation and stomatal opening (Pieruschka et al., 2010). VPD, the gradient of water vapor concentration from the leaf to the air, is the driving force for transpiration and also affects stomatal regulation (Bunce, 2006; Taiz and Zeiger, 2006). Temperature can affect evapotranspiration and plant metabolic activity (Allen et al., 1998; van Iersel, 2003). Wind speed and soil water content also affect plant water use (Andersson, 2011; van Iersel et al., 2010). However, air flow in greenhouses is highly variable (Fernandez and Bailey, 1994), making it difficult to quantify, and providing sufficient water can prevent water availability from becoming limiting.

Many researchers have developed models predicting irrigation needs by estimating evapotranspiration (ET) using environmental factors (Jones and Tardieu, 1998). The most common method of calculating ET is the 
Penman-Monteith equation, recommended by the United Nations Food and Agriculture Organization (Allen et al., 1998). The PenmanMonteith equation is an energy balance-based method and requires good estimates of an empirical crop coefficient $(\mathrm{Kc})$ that incorporates specific features of a crop (Allen et al., 1998). This equation was developed for field crops with large, uniform canopies and many field crops have relatively well-established $\mathrm{Kc}$ values. However, Kc values for ornamental plants have high variability and require a large amount of empiricism with recalibration (Baille et al., 1994), and the adoption of this approach for ornamental plant production has been questioned (Bacci et al., 2008; Schuch and Burger, 1997).

For estimation of water use of ornamentals in greenhouses, researchers have developed models by modifying the Penman-Monteith equation (Bacci et al., 2008; Baille et al., 1994; Beeson and Brooks, 2008; Krügera et al., 1999; Rouphael et al., 2008). Baille et al. (1994) derived models for Begonia $\times$ hiemalis, Cyclamen persicum, Gardenia jasminoides, Sinningia speciosa, Hibiscus rosa-sinensis, Impatiens $\times$ novae-guinea, Pelargonium $\times$ hortorum, Euphorbia pulcherrima, and Shefflera arboricola based on a simplified Penman-Monteith equation with radiation and VPD as the two main environmental factors and leaf area index (LAI) as the plant factor for determining hourly ET. Their model predicted the hourly ET rate of these nine species during the daytime with an $R^{2}$ ranging from 0.87 to 0.97. Although LAI is a good indication of plant size, it can be difficult and laborious to measure, especially for commercial growers (Rouphael and Colla, 2004). Therefore, a more practical model with easily acquirable variables would facilitate the use of the estimation of water use in greenhouse ornamental production.

In this study, we used a capacitance sensorbased automatic irrigation system (Nemali and van Iersel, 2006) to quantify the irrigation amount. This automated irrigation system maintained $\theta$ at a stable level regardless of plant water use while quantifying the amount of water needed to maintain $\theta$. The objective of this study was to develop an easy-to-use model that describes the daily water requirement of petunia based on easily acquirable parameters (DLI, VPD, temperature, and DAP). Such model-based quantitative information regarding plant water use may assist greenhouse growers in making better irrigation decisions.

\section{Materials and Methods}

Plant material. Two petunia cultivars (Single Dreams Pink and Prostrate Easy Wave Pink) were used to quantify the water use of two cultivars with different growth habits (upright, 'Single Dreams Pink' and spreading 'Prostrate Easy Wave Pink'; Griesbach, 2006). Seedlings in 288-plug trays were obtained from a commercial greenhouse (C. Raker and Sons, Litchfield, MI) and transplanted into 10-, 12.5-, and 15-cm diameter, round plastic containers (volume of 420, 767, and $1320 \mathrm{~mL}$, respectively). Containers were filled with soilless substrate (Fafard 2P; 60\% peat and 40\% perlite; Fafard, Anderson, SC) with controlled-release fertilizer $(14.0 \mathrm{~N}-6.2 \mathrm{P}-11.6 \mathrm{~K}$; Osmocote 14-14-14; Scotts, Marysville, $\mathrm{OH}$ ) incorporated at a rate of $7.7 \mathrm{~g} \cdot \mathrm{L}^{-1}$. Three different container sizes were used to quantify the effect of container size on water use. Plants were grown in a glass greenhouse for $45 \mathrm{~d}$ (10 Oct. to 24 Nov. 2008) with a capacitance sensor-controlled irrigation system. To allow the seedlings to get established, the plants were hand-irrigated for $5 \mathrm{~d}$ after transplanting, after which the sensor-controlled irrigation system was used.

Each experimental unit had 12 plants in three rows of four pots, and only the two pots in the center of this group were used for data collection to avoid edge effects. During the growing period, average temperature and relative humidity were $18.3 \pm 1.6{ }^{\circ} \mathrm{C}$ and $59 \% \pm$ $11 \%$, and average DLI in the greenhouse was $12.5 \pm 5.7 \mathrm{~mol} \cdot \mathrm{m}^{-2} \cdot \mathrm{d}^{-1}$ (average $\pm \mathrm{SD}$ ).

Automatic irrigation system. A previously described automated irrigation system (Nemali and van Iersel, 2006) was modified for this study. Two multiplexers (AM 16/32; Campbell Scientific, Logan, UT) were connected to a data logger (CR10; Campbell Scientific), and 32 EC-5 capacitance soil moisture sensors (EC-5; Decagon Devices, Pullman, WA) were connected to each multiplexer. The two center pots in each of the 32 experimental units had one capacitance sensor each, which measured $\theta$ every $10 \mathrm{~min}$. Also connected to the data logger were two relay drivers (SDMCD16 AC/DC controller; Campbell Scientific), which could control power to 16 solenoid valves (X-13551-72; Dayton Electric Company, Niles, IL) each. When the average $\theta$ reading of the two capacitance sensors in an experimental unit dropped below $0.40 \mathrm{~m}^{3} \cdot \mathrm{m}^{-3}$, the data logger sent a signal to the relay driver to power the solenoid valve controlling the irrigation of that particular experimental unit for $4 \mathrm{~s}$. Each container received water from a drip stake with a pressure-compensated emitter (Netafim 8 L/H 4-way Multi-Outlet-
Dripper assembly; Netafim USA, Fresno, CA). Each irrigation application was recorded by the data logger and used to calculate the daily amount of water applied to the plants. We had determined previously that a $\theta$ of $0.40 \mathrm{~m}^{3} \cdot \mathrm{m}^{-3}$ resulted in good growth of bedding plants with minimal or no leaching (Burnett and van Iersel, 2008; Kim and van Iersel, 2009; Nemali and van Iersel, 2008; van Iersel et al., 2010).

Four $\mathrm{d}$ after starting the automated irrigation, $\theta$ reached $0.40 \mathrm{~m}^{3} \cdot \mathrm{m}^{-3}$ in all experimental units and data collection occurred for the next $35 \mathrm{~d}$. The cumulative irrigation amount was calculated based on the last $35 \mathrm{~d}$ of the experiment.

To control irrigation precisely and prevent leaching, solenoid valves were opened for $4 \mathrm{~s}(2.4 \mathrm{~mL} /$ plant/application $)$ as needed. This provided enough water to maintain stable $\theta$ s throughout most of the study. However, late in the growing cycle, plant water use during the daytime exceeded the capacity of the irrigation system to supply water with a 4-s irrigation duration. Thus, at $38 \mathrm{DAP}$ (17 Nov.), the irrigation duration was increased to $6 \mathrm{~s}$ (3.6 $\mathrm{mL} /$ plant/application) to assure that stable $\theta$ s could be maintained. When more than 14 solenoid valves were opened at the same time, irrigation amount was decreased as a result of a lack of water pressure, and the irrigation amount was adjusted for the number of opened valves.

Measurements. Temperature and relative humidity (Vaisala HMP50; Vaisala Inc., Woburn, MA) were measured every $10 \mathrm{~min}$ and photosynthetic photon flux $(P P F)$ (QSOSun; Apogee Instruments, Logan, UT) was measured every $4 \mathrm{~s}$. The data logger also recorded daily average, maximum, and minimum temperature; relative humidity; and light intensity. VPD was calculated based on the average temperature and relative humidity in a day. DLI was calculated by integrating all $P P F$ data in a day. Environmental conditions are summarized in Figure 1.

The data logger recorded averaged $\theta$ every $2 \mathrm{~h}$ and irrigation events every $10 \mathrm{~min}$, and the daily irrigation volume for each

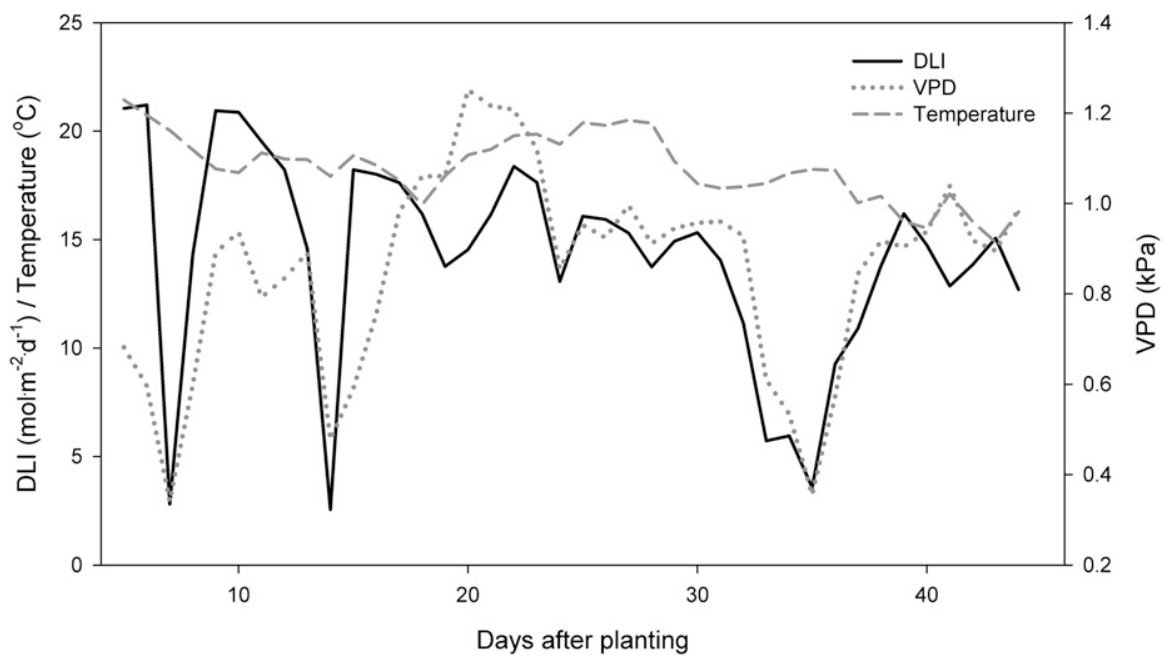

Fig. 1. Environmental conditions (DLI, daily light integral; VPD, vapor pressure deficit; and temperature) in the greenhouse during the experiment. VPD and temperature were averaged over the entire day. 
experimental unit was calculated from these data.

At harvest, the two plants with capacitance sensors in each experimental unit were harvested. Growth parameters, including shoot fresh and dry weight, leaf size of the uppermost fully expanded leaves, and total leaf area (LI3100; LI-COR, Lincoln, NE), were measured.

Statistical analysis. The experimental design was a randomized complete block with a split plot with four replicates. Container size was used as the main blocking factor, and the two cultivars were the split plot. The effects of container size and cultivar on growth parameters were analyzed by three-way analysis of variance (proc ANOVA; SAS, SAS Institute, Cary, NC). When ANOVA indicated significance, means were separated using pairwise comparisons at $\alpha=0.05$. The effects of container size and cultivar on the cumulative irrigation amount and the maximum and minimum DWU were also analyzed following the same procedure. The relationship between cumulative irrigation amount and shoot dry weight was analyzed using linear regression.

Multiple regression ( $\alpha=0.05$, proc REG; SAS) was used to describe the effects of DAP, container size, and environmental conditions on DWU. DAP was used as a proxy for plant size, and DLI and daily averages of VPD and temperature were the environmental variables used. We developed separate models for each cultivar to account for differences in DWU between two cultivars. The relationship between DWU and other variables (DAP, DLI, temperature, VPD, and container size) and their interaction terms was analyzed with Pearson's correlation (proc CORR; SAS). To account for the effect of container size on DWU, we tested for correlations between DWU and container diameter, surface area, and volume. Container diameter had the strongest correlation with DWU and was used for further model development. Two different models were developed for each cultivar. The simpler model included DAP, container size, DLI, VPD, and temperature, whereas the other model included the same variables as well as DAP interactions with container size, DLI, VPD, and temperature. DWU regression models for each cultivar were determined by backward selection using proc REG in SAS. Partial $R^{2}$ was used to quantify the contribution of each variable to the model.

\section{Results and Discussion}

Irrigation system performance. The irrigation system constantly maintained $\theta$ close to $0.40 \mathrm{~m}^{3} \cdot \mathrm{m}^{-3}$ (Fig. 2). Fluctuations in $\theta$ were small as a result of the low irrigation volume per application. Jones (2004) indicated that frequent irrigation with small amounts can provide precise irrigation, and the measured $\theta$ was maintained at $0.401 \pm 0.003$ (mean \pm SD) $\mathrm{m}^{3} \cdot \mathrm{m}^{-3}$ for 'Single Dreams Pink' without any leaching. However, starting on Day 26, the $\theta$ of 'Prostrate Easy Wave Pink' dropped below $0.40 \mathrm{~m}^{3} \cdot \mathrm{m}^{-3}$ (to $0.36 \mathrm{~m}^{3} \cdot \mathrm{m}^{-3}$ ) on sunny days (Fig. 2B), when the ET during the

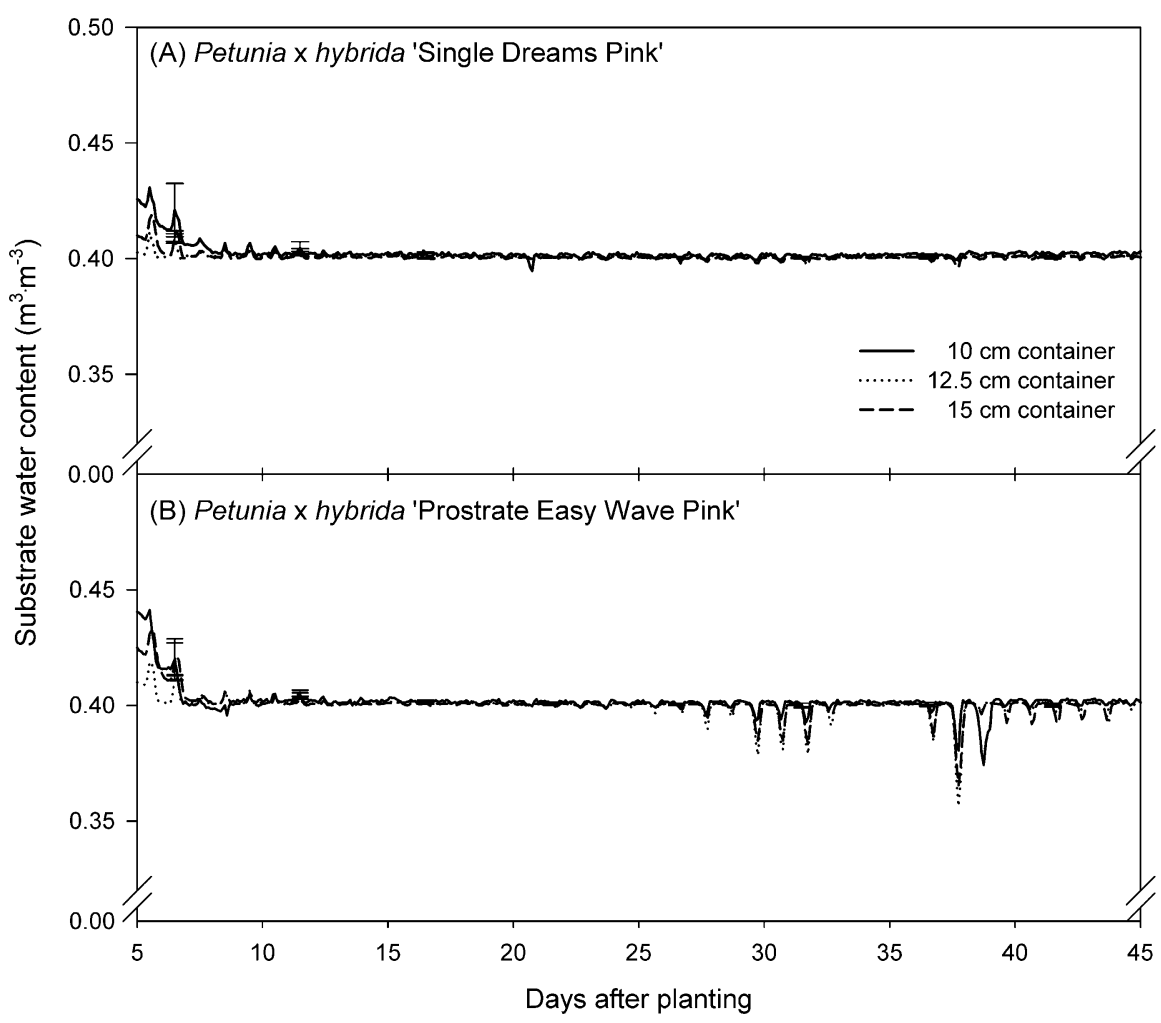

Fig. 2. Average substrate water content $(\theta, \mathrm{n}=4)$ of two petunia cultivars in 10-, 12.5-, and 15-cm containers as maintained by a capacitance sensor-controlled automated irrigation system. Plants were irrigated when $\theta$ dropped below $0.40 \mathrm{~m}^{3} \cdot \mathrm{m}^{-3}$. Selected error bars (every $5 \mathrm{~d}$ at noon) indicate the SE. Most error bars are not visible as a result of small SES.

daytime exceeded the ability of the irrigation system to replenish the $\theta$. To increase the amount of water that could be applied, the irrigation time was increased to $6 \mathrm{~s}$ at 38 DAP, but $\theta$ still dropped below $0.40 \mathrm{~m}^{3} \cdot \mathrm{m}^{-3}$. The $\theta$ increased back to $0.40 \mathrm{~m}^{3} \cdot \mathrm{m}^{-3}$ at night, and this decrease in $\theta$ during the day therefore did not affect the measured DWU of the plants nor was the decrease in $\theta$ likely large enough to significantly affect plant growth.

Plant growth and water use. At harvest, shoot fresh and dry weights of the plants in $15-\mathrm{cm}$ containers were greater than those in smaller containers (Table 1). Although shoot fresh weight was similar between the two cultivars, shoot dry weight of 'Prostrate Easy Wave Pink' was greater than that of 'Single Dreams Pink'. Leaf size and total leaf area of both cultivars were larger in bigger containers. Similar to shoot dry weight, total leaf area was larger in 'Prostrate Easy Wave Pink' than 'Single Dreams Pink'. Less shoot growth (dry mass and leaf area) in smaller containers was likely the result of root growth restriction (Latimer, 1991; Ray and Sinclair, 1998; van Iersel, 1997). Because $\theta$ was maintained close to $0.40 \mathrm{~m}^{3} \cdot \mathrm{m}^{-3}$ throughout the growing period (i.e., no drought stress), the smaller leaf size in smaller containers was also likely the result of the greater effect of root restriction.

Over the 46-d growing period, the minimum DWU was similar among container sizes and cultivars (Table 1). All plants used the least water (from 4.8 to $13.8 \mathrm{~mL} / \mathrm{plant}$ ) at 7 DAP (Fig. 3), which was a day with a low
DLI $\left(2.81 \mathrm{~mol} \cdot \mathrm{m}^{-2} \cdot \mathrm{d}^{-1}\right)$. In contrast, the day of maximum DWU differed among the experimental units. However, maximum DWU in all cases occurred later in the study (DAP greater than 35 ), on days with high DLI (greater than $14 \mathrm{~mol} \cdot \mathrm{m}^{-2} \cdot \mathrm{d}^{-1}$ ), indicating that water use depends on plant size and light level. The maximum DWU amount ranged from $67.9 \mathrm{~mL}$ ('Single Dreams Pink' in 10-cm container) to $218 \mathrm{~mL}$ ('Prostrate Easy Wave Pink' in $15-\mathrm{cm}$ container). The maximum DWU was greater in larger containers and in 'Prostrate Easy Wave Pink' compared with 'Single Dreams Pink' (Table 1). Maximum DWU was positively correlated with leaf area $(r=0.9, P<0.0001)$.

As a result of their size, plants in larger containers required more irrigation, and 'Prostrate Easy Wave Pink' used more water than 'Single Dreams Pink' (Table 1). Differences in cumulative irrigation amount were similar to those in shoot dry weight and total leaf area. 'Single Dreams Pink' and 'Prostrate Easy Wave Pink' in $15-\mathrm{cm}$ containers used $60 \%$ and $78 \%$, respectively, more water than plants in $10-\mathrm{cm}$ containers. Shoot dry weight was positively correlated with cumulative irrigation amount, regardless of container size (Fig. $4, P<0.001$ ). The slope of the regression line $\left(2.46 \mathrm{~g} \cdot \mathrm{L}^{-1}\right)$ is a measure of water use efficiency (i.e., increase in shoot dry weight per liter of water), accounting for both evaporation from the substrate and transpiration from the plants. These results indicate that container size and cultivar had little or no effect on water use 
Table 1. Growth parameters and daily water use (DWU) of two petunia cultivars at harvest. ${ }^{z}$

\begin{tabular}{|c|c|c|c|c|c|c|c|}
\hline Cultivar and container size & $\begin{array}{c}\text { Shoot fresh } \\
\text { wt }(g)\end{array}$ & $\begin{array}{c}\text { Shoot dry } \\
\text { wt (g) }\end{array}$ & $\begin{array}{l}\text { Leaf size } \\
\left(\mathrm{cm}^{2}\right)\end{array}$ & $\begin{array}{l}\text { Total leaf } \\
\text { area }\left(\mathrm{cm}^{2}\right)\end{array}$ & $\begin{array}{l}\text { Minimum } \\
\text { DWU (mL) }\end{array}$ & $\begin{array}{l}\text { Maximum } \\
\text { DWU (mL) }\end{array}$ & $\begin{array}{c}\text { Cumulative } \\
\text { water use (L) }\end{array}$ \\
\hline $10 \mathrm{~cm}$ & $60 \mathrm{c}$ & $3.73 \mathrm{c}$ & $11.8 \mathrm{bc}$ & $727 \mathrm{~d}$ & $4.8 \mathrm{~b}$ & $68 \mathrm{c}$ & $1.70 \mathrm{c}$ \\
\hline $12.5 \mathrm{~cm}$ & $88 \mathrm{~b}$ & $5.17 \mathrm{bc}$ & $14.4 \mathrm{~b}$ & $1003 \mathrm{~cd}$ & $7.2 \mathrm{ab}$ & $99 \mathrm{c}$ & $2.37 \mathrm{bc}$ \\
\hline \multicolumn{8}{|l|}{ Prostrate Easy Wave Pink } \\
\hline $10 \mathrm{~cm}$ & $54 \mathrm{c}$ & $5.02 \mathrm{bc}$ & $9.8 \mathrm{c}$ & $1000 \mathrm{~cd}$ & $6.6 \mathrm{ab}$ & $111 \mathrm{c}$ & $2.29 \mathrm{bc}$ \\
\hline $12.5 \mathrm{~cm}$ & $97 \mathrm{~b}$ & $8.25 \mathrm{a}$ & $14.9 \mathrm{~b}$ & $1583 \mathrm{~b}$ & $6.6 \mathrm{ab}$ & $165 \mathrm{~b}$ & $3.60 \mathrm{a}$ \\
\hline Container size & $* * *$ & ** & ** & $* * *$ & ** & $* *$ & $* * *$ \\
\hline Cultivar & NS & $* * *$ & NS & $* * *$ & NS & $* * *$ & $* * *$ \\
\hline Cultivar $\times$ container size & NS & NS & NS & NS & NS & NS & NS \\
\hline
\end{tabular}

${ }^{\mathrm{z}}$ Means followed by the same letter are not significantly different $(P=0.05)$. *** and ** indicate significance at $P<0.001$ and $P<0.01$ and NS represents nonsignificance.

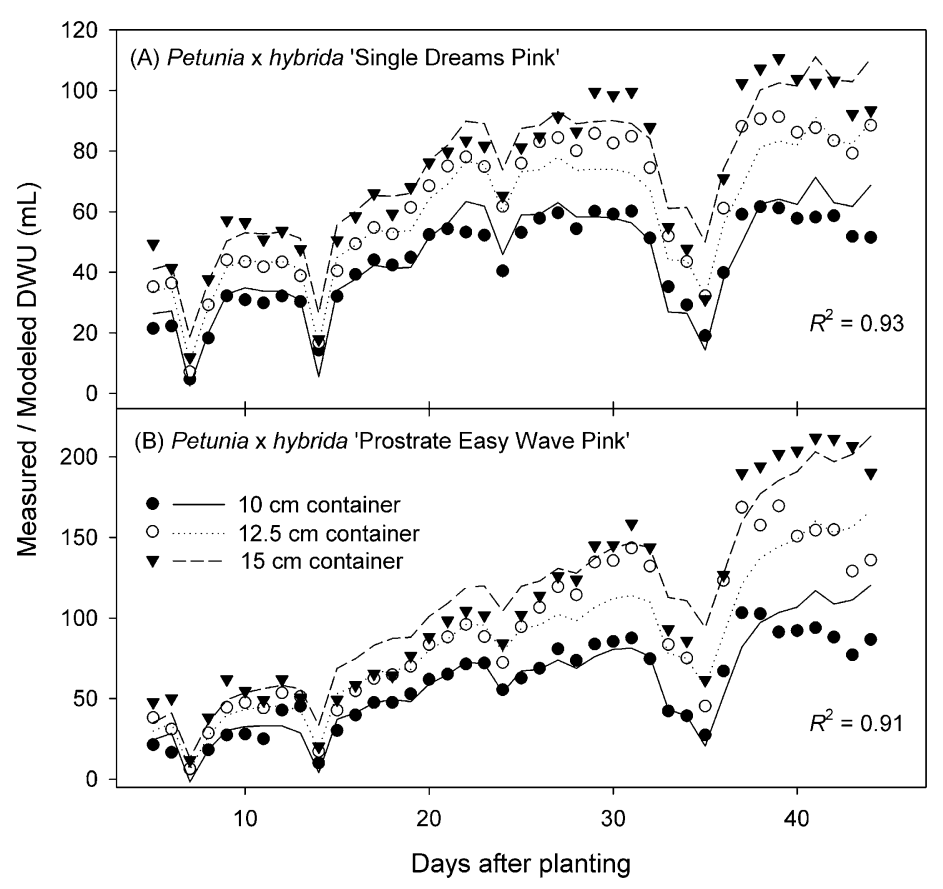

Fig. 3. Measured daily water use (DWU) (symbols) and modeled DWU (lines) of two petunia cultivars (Single Dreams Pink and Prostrate Easy Wave Pink) grown in three container sizes. The models were based on the effects of days after planting (DAP), container size, environmental conditions, and interactions between DAP and environmental conditions. See Table 4 for details of the models.

efficiency. This water use efficiency is similar to that of petunia 'Velvet Carpet' $(2.5$ g. $\mathrm{L}^{-1}$; van Iersel et al., 2010) and Pelargonium $\times$ hortorum $\left(2.2 \mathrm{~g} \cdot \mathrm{L}^{-1}\right.$; Rouphael et al., 2008).

Models with main effects. Models using only main effects (DAP, container size, DLI, VPD, and temperature) explained $89 \%$ and $83 \%$ of the variation in DWU of 'Single Dreams Pink' and 'Prostrate Easy Wave Pink', respectively (Table 3). Temperature was not significant in the 'Prostrate Easy Wave Pink' model. For both cultivars, DAP had the highest partial $R^{2}$ followed by container size (Table $3)$, indicating the importance of plant size (sum of partial $R^{2}$ of DAP and container size = 0.60 and 0.74 for 'Single Dreams Pink' and 'Prostrate Easy Wave Pink', respectively). DAP was positively correlated with DWU (Table 2; $r=0.619$ and 0.758 for 'Single Dreams Pink' and 'Prostrate Easy Wave Pink', respectively), likely because the increasing plant size over time increased DWU. Container size was also positively correlated with DWU $(r=0.472$ and 0.401 for 'Single Dreams Pink' and 'Prostrate Easy Wave Pink', respectively), because smaller containers limited plant growth. Previous research reported that transpiration decreased in Zea mays, Glycine max (Ray and Sinclair, 1998) and Tagetes erecta seedlings (Latimer, 1991) as container size decreased. Baille et al. (1994) used LAI to account for plant size in their water use models of ornamental plants, but frequent measurement of LAI for greenhouse production is impractical in a production greenhouse (Rouphael and Colla, 2004). Alternatively, digital imaging can be used to monitor plant size and growth (Klassen et al., 2003), but this is not yet commonly used in greenhouses. In our study, DAP and container size were correlated with DWU and together appeared to be a good proxy for plant size of petunia.

It was previously reported that DLI is the most important environmental factor affecting evapotranspiration (Kim and van Iersel, 2009; Löfkvist et al., 2009; van Iersel et al., 2010). However, DLI had a weak or no correlation with DWU in this study (Table 2; $r=$ 0.201 and $-0.001, P=0.028$ and 0.989 for 'Single Dreams Pink' and 'Prostrate Easy Wave Pink', respectively). This low correlation was mainly the result of the negative correlation between DLI and DAP $(r=-0.36$, $P<0.001)$. Because this study was conducted in the fall, daylength and DLI generally decreased throughout the experiment (Fig. 1). Furthermore, there were only a few overcast days, resulting in relatively little variation in DLI. Despite the lack of a strong correlation between DLI and DWU, DLI was the most important environmental factor in the model with a partial $R^{2}$ of 0.20 and 0.08 for 'Single Dreams Pink' and 'Prostrate Easy Wave Pink', respectively.

VPD was positively correlated with DWU but had a partial $R^{2}$ of only 0.07 and 0.01 for 'Single Dreams Pink' and 'Prostrate Easy Wave Pink', respectively. This low partial $R^{2}$ is surprising, because VPD is the main driving force for the diffusion of water from leaves to the air (Taiz and Zeiger, 2006). Previous transpiration models used VPD to explain convective water loss from leaves in greenhouse crops (Baille et al., 1994; Bakker, 1986; Lorenzo, 1998), and VPD plays an important role in the Penman-Monteith equation as well (Allen et al., 1998). High VPD can decrease stomatal conductance under drought (Bunce, 2006), transpiration of Pelargonium zonale (Montero et al., 2001) and Cucumis sativus (Medrano et al., 2005) and VPD were correlated, even when VPD was greater than $3 \mathrm{kPa}$. In our study, $\theta$ was sufficient throughout the experiment and average daily VPD ranged from 0.2 to $1.2 \mathrm{kPa}$ and was unlikely to restrict stomatal opening.

Temperature was negatively correlated with DWU (Table 2) but had little effect on DWU, with a partial $R^{2}$ of only 0.01 for 'Single Dreams Pink', and was not significant for 'Prostrate Easy Wave Pink' (Table 3). Similar to the decrease in DLI during the experiment, temperature gradually decreased as 


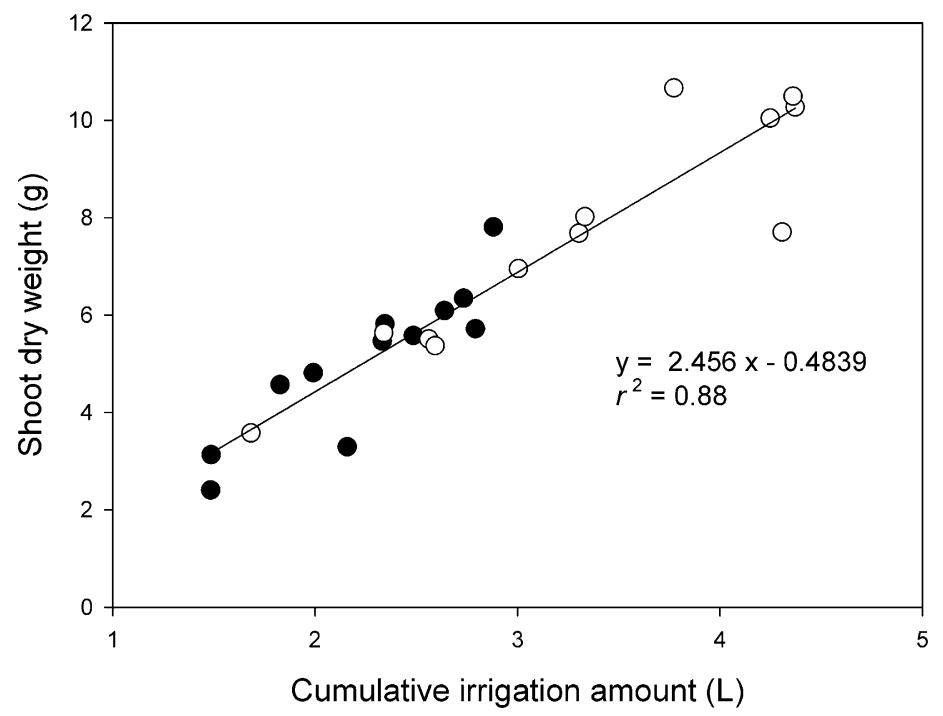

Fig. 4. Shoot dry weight of two petunia cultivars as a function of cumulative irrigation amount. Solid circles represent 'Single Dreams Pink' and open circles represent 'Prostrate Easy Wave Pink'. The regression line was fitted through the data for both cultivars $(P<0.001)$; the slope of the regression line is a measure of water use efficiency.

Table 2. Pearson's correlation coefficients for daily water use of two petunia cultivars (DWU ${ }^{\text {SD }}$, daily water use of 'Single Dreams Pink'; DWU ${ }^{\mathrm{EW}}$, daily water use of 'Prostrate Easy Wave Pink'), days after planting (DAP), container diameter, and environmental variables (DLI, daily light integral; VPD, vapor pressure deficit; temperature). ${ }^{\mathrm{z}}$

\begin{tabular}{|c|c|c|c|c|c|c|c|}
\hline \multirow[b]{2}{*}{ Variables } & \multirow[b]{2}{*}{ Range } & \multirow[b]{2}{*}{$\mathrm{DWU}^{\mathrm{SD}}$} & \multirow[b]{2}{*}{ DWU ${ }^{\mathrm{EW}}$} & \multicolumn{4}{|c|}{ Single variables } \\
\hline & & & & DAP & $\begin{array}{c}\text { DLI } \\
\end{array}$ & VPD & $\overline{\text { Temperature }}$ \\
\hline$\overline{\mathrm{DAP}}$ & $5-44 d$ & $\begin{array}{l}0.619 \\
* * *\end{array}$ & $\begin{array}{l}0.758 \\
* * *\end{array}$ & - & & & \\
\hline DLI & $2.6-21.2 \mathrm{~mol} \cdot \mathrm{m}^{-2} \cdot \mathrm{d}^{-1}$ & $\begin{array}{c}0.201 \\
*\end{array}$ & $\begin{array}{c}-0.001 \\
\text { NS }\end{array}$ & $\begin{array}{c}-0.357 \\
* * *\end{array}$ & - & & \\
\hline VPD & $0.34-1.25 \mathrm{kPa}$ & $\begin{array}{l}0.609 \\
* * *\end{array}$ & $\begin{array}{l}0.421 \\
* * *\end{array}$ & $\begin{array}{c}0.193 \\
*\end{array}$ & $\begin{array}{c}0.528 \\
* * *\end{array}$ & - & \\
\hline Temperature & $14.9-21.4^{\circ} \mathrm{C}$ & $\begin{array}{l}-0.326 \\
* * *\end{array}$ & $\begin{array}{c}-0.489 \\
* * *\end{array}$ & $\begin{array}{c}-0.642 \\
* * *\end{array}$ & $\begin{array}{l}0.207 \\
*\end{array}$ & $\begin{array}{c}-0.121 \\
\text { NS }\end{array}$ & - \\
\hline Container diameter & $10-15 \mathrm{~cm}$ & $\begin{array}{l}0.472 \\
* * *\end{array}$ & $\begin{array}{l}0.401 \\
* * *\end{array}$ & NA & NA & NA & NA \\
\hline
\end{tabular}

z*** and * indicate significance at $P<0.001$ and $P<0.05$, and NS represents non-significance. $\mathrm{NA}=$ not applicable, because container size did not change over the course of the experiment.

Table 3. Regression coefficients $(\beta)$ and partial $R^{2}$ values for the variables in daily water use regression models of petunia 'Single Dreams Pink' and 'Prostrate Easy Wave Pink' based on the main effects of days after planting, container size, and environmental conditions.

\begin{tabular}{lrrrrrrc}
\hline & \multicolumn{3}{c}{ Single Dreams Pink } & & \multicolumn{3}{c}{ Prostrate Easy Wave Pink } \\
\cline { 2 - 7 } Variable (unit) & \multicolumn{1}{c}{$\beta$} & \multicolumn{1}{c}{$P$} & Partial $R^{2}$ & & \multicolumn{1}{c}{$P$} & Partial $R^{2}$ \\
\hline Days after planting (d) & 1.52 & $<0.001$ & 0.38 & & 3.44 & $<0.001$ & 0.58 \\
Daily light integral $\left(\mathrm{mol} \cdot \mathrm{m}^{-2} \cdot \mathrm{d}^{-1}\right)$ & 1.25 & $<0.001$ & 0.20 & & 2.09 & $<0.001$ & 0.08 \\
Vapor pressure deficit $(\mathrm{kPa})$ & 40.40 & $<0.001$ & 0.07 & & 37.19 & 0.002 & 0.01 \\
Temperature $\left({ }^{\circ} \mathrm{C}\right)$ & 2.08 & 0.002 & 0.01 & - & - & - \\
Container diameter $(\mathrm{cm})$ & 5.66 & $<0.001$ & 0.22 & & 9.78 & $<0.001$ & 0.16 \\
Intercept & -139.60 & $<0.001$ & & -183.04 & $<0.001$ & - \\
& & & & & & \\
Total $R^{2}$ & & 0.89 & & & 0.83 & \\
\hline
\end{tabular}

a result of seasonal weather changes, thus resulting in lower temperatures during the period that plants had the highest DWU (Fig. 1). Furthermore, relatively stable temperatures in the greenhouse may have made it difficult to detect a temperature effect on transpiration.

Although the coefficients of determination of the model were 0.89 and 0.83 for 'Single Dreams Pink' and 'Prostrate Easy Wave Pink', respectively, the models for both cultivars overestimated DWU when DWU was low and underestimated DWU when it was high (Fig. 5A-B).

Model selection with days after planting interactions. Including interactions between DAP and other variables improved the model for both cultivars. The DWU model for 'Single Dreams Pink' included the main effects of DAP, DLI, and container size as well as the DAP interactions with DLI, VPD, container size, and temperature and explained $93 \%$ of the variation in DWU (Fig. 3A). For 'Pros- trate Easy Wave Pink', DAP, DLI, VPD, and DAP interactions with VPD and container size were significant in its DWU model and explained $91 \%$ of the variation (Fig. 3B)

Similar to the models with main effects only, DAP and container size had the largest contribution to the model (Table 4; combined partial $R^{2}$ for DAP, container size, and DAP $\times$ container size $=0.62$ and 0.80 for 'Single Dreams Pink' and 'Prostrate Easy Wave Pink', respectively). DAP interaction with container size was significant in both cultivars, indicating that the effect of container size became more important over time as root restriction of growth becomes more important. Container size affected growth of Salvia splendens as early as 18 DAP and those effects increased over time (van Iersel, 1997).

For both cultivars, DLI was the most important environmental variable in the DWU model (Table 4; partial $R^{2}=0.20$ and 0.08 for 'Single Dreams Pink' and 'Prostrate Easy Wave Pink', respectively), and for 'Single Dreams Pink', the effect of DLI on DWU depended on DAP $($ DAP $\times$ DLI interaction, partial $R^{2}=0.05$ ). The main effect of VPD was statistically significant for 'Prostrate Easy Wave Pink' but had little practical importance (partial $R^{2}=0.01$ ). There also was a DAP $\times V P D$ interaction, indicating that the VPD effect increased later in the study, but this effect was small (partial $R^{2}=0.03$ for both cultivars). The interactions between DAP and DLI and VPD indicate that these two environmental factors became more important over time as a result of increasing plant size. Water use is likely to depend on the amount of light reaching the plant and thus on both DLI and leaf surface area. DLI and VPD were positively correlated $(r=0.528, P<0.001)$, which caused difficulties in partitioning the effects of these two environmental factors. Modification of individual environmental factors [e.g., DLI by shading or VPD using (de)humidification] may be beneficial to minimize multicollinearity among the environmental variables to more precisely determine their individual contributions to DWU.

Temperature effects were not significant for 'Prostrate Easy Wave Pink', whereas there was a significant DAP $\times$ temperature interaction for 'Single Dreams Pink'. As DAP increased, the effect of temperature on DWU of 'Single Dreams Pink' increased, but the overall effect was small (partial $R^{2}=0.02$ ). As mentioned, the effect of temperature may have been small as a result of the relatively stable greenhouse temperatures. Our results support that DLI is the most important environmental variable affecting water use, but temperature might have played a bigger role if it had varied more

The models with DAP interaction terms fitted better than the models with main effects only. The models with DAP interaction terms still tended to overestimate DWU when DWU was low and underestimate DWU when it was high (Fig. 5C-D), like the models with main effects. However, the slope of the regression line between the measured and modeled DWU was closer to 1 when interaction terms were 
Table 4. Regression coefficients $(\beta)$ and partial $R^{2}$ values for the variables in daily water use regression models of petunia 'Single Dreams Pink' and 'Prostrate Easy Wave Pink' based on the main effects of days after planting (DAP), container size, and environmental conditions (DLI, daily light integral; VPD, vapor pressure deficit; temperature) as well as their interactions with DAP.

\begin{tabular}{|c|c|c|c|c|c|c|}
\hline \multirow[b]{2}{*}{ Variable (unit) } & \multicolumn{3}{|c|}{ Single Dreams Pink } & \multicolumn{3}{|c|}{ Prostrate Easy Wave Pink } \\
\hline & $\beta$ & $P$ & Partial $R^{2}$ & $\beta$ & $P$ & Partial $R^{2}$ \\
\hline \multicolumn{7}{|l|}{ Main effects } \\
\hline $\operatorname{DAP}(d)$ & -3.48 & $<0.001$ & 0.38 & -4.75 & $<0.001$ & 0.58 \\
\hline DLI $\left(\mathrm{mol} \cdot \mathrm{m}^{-2} \cdot \mathrm{d}^{-1}\right)$ & 1.03 & $<0.001$ & 0.20 & 1.94 & $<0.001$ & 0.08 \\
\hline VPD (kPa) & - & - & - & -41.24 & 0.008 & 0.01 \\
\hline Temperature $\left({ }^{\circ} \mathrm{C}\right)$ & - & - & - & - & - & - \\
\hline Container size $(\mathrm{cm})$ & 2.24 & 0.002 & 0.22 & - & - & - \\
\hline \multicolumn{7}{|l|}{ DAP interactions } \\
\hline $\mathrm{DAP} \times \mathrm{DLI}$ & 0.03 & 0.041 & 0.05 & - & - & - \\
\hline $\mathrm{DAP} \times \mathrm{VPD}$ & 1.31 & $<0.001$ & 0.03 & 3.65 & $<0.001$ & 0.03 \\
\hline DAP $\times$ temperature & 0.11 & $<0.001$ & 0.02 & - & - & - \\
\hline DAP $\times$ container size & 0.14 & $<0.001$ & 0.02 & 0.42 & $<0.001$ & 0.22 \\
\hline Intercept & -26.77 & 0.008 & - & 2.16 & 0.860 & - \\
\hline Total $R^{2}$ & & 0.93 & & & 0.91 & \\
\hline
\end{tabular}

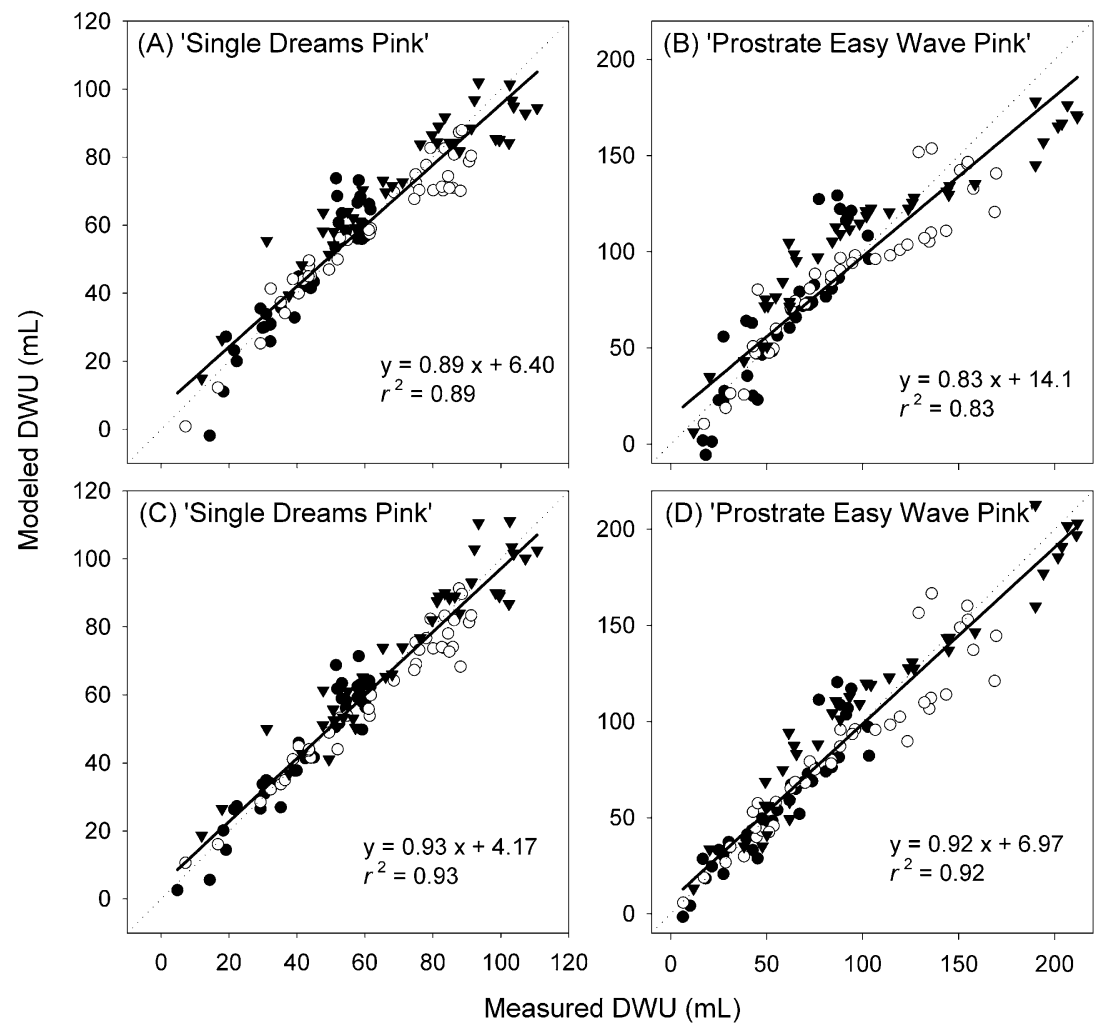

Fig. 5. Measured and modeled daily water use (DWU) of two petunia cultivars (Single Dreams Pink and Prostrate Easy Wave Pink) grown in three container sizes $(\bullet, 10 \mathrm{~cm} ; \circ, 12.5 \mathrm{~cm}$; and $\boldsymbol{\nabla}, 15-\mathrm{cm}$ container diameter, respectively). Models were developed using multiple regression with the main effects of days after planting (DAP), daily light integral (DLI), vapor pressure deficit (VPD), container size, and temperature (A-B) or with these terms and interactions of the environmental factors and container size with DAP $(\mathbf{C}-\mathbf{D})$. See Tables 3 and 4 for details of the models. The solid line indicates the regression line fitted through the data $(\mathrm{n}=120)$.

included. These models suggest that DAP, container size, and their interaction may be a good proxy for plant size, whereas DLI and VPD and their interactions with DAP can account for most of the environment-induced variation in DWU of petunia.

\section{Conclusions}

We developed a model of petunia DWU, which can be used to quantify how environ-
Although this model explained most of the fluctuations in DWU, the ability of the model to predict water use of petunias needs to be evaluated with independent data sets. Nonetheless, this model can provide greenhouse growers quantitative estimates of the water requirements of their crop and may help to irrigate more efficiently.

\section{Literature Cited}

Allen, R.G., L.S. Pereira, D. Raes, and M. Smith. 1998. Crop evapotranspiration-Guidelines for computing crop water requirements-FAO Irrigation and drainage paper 56. FAO, Rome, Italy.

Andersson, N.E. 2011. The influence of water stress and air velocity on growth of Impatiens walleriana and Petunia $\times$ hybrid. Sci. Hort. 128:146-151.

Bacci, L., P. Battista, and B. Rapi. 2008. An integrated method for irrigation scheduling of potted plants. Sci. Hort. 116:89-97.

Baille, M., A. Baille, and J.C. Laury. 1994. A simplified model for predicting evapotranspiration rate of nine ornamental species vs. climate factors and leaf area. Sci. Hort. 59:217-232.

Bakker, J.C. 1986. Measurement of canopy transpiration or evapotranspiration in greenhouses by means of a simple vapour balance model. Agr. For. Meteorol. 37:133-141.

Beeson, R.C. Jr. and J. Brooks. 2008. Evaluation of a model based on reference crop evapotranspiration (ETo) for precision irrigation using overhead sprinklers during nursery production of Ligustrum japonica. Acta Hort. 792:85-90.

Bilderback, T.E. 2002. Water management is key in reducing nutrient runoff from container nurseries. HortTechnology 12:541-544.

Blonquist, J.J.M., S.B. Jones, and D.A. Robinson. 2006. Precise irrigation scheduling for turfgrass using a subsurface electromagnetic soil moisture sensor. Agr. Water Mgt. 84:153-165.

Bunce, J.A. 2006. How do leaf hydraulics limit stomatal conductance at high water vapour pressure deficits? Plant Cell Environ. 29:1644-1650.

Burnett, S.E. and M.W. van Iersel. 2008. Morphology and irrigation efficiency of Gaura lindheimeri grown with capacitance sensor-controlled irrigation. HortScience 43:1555-1560.

Fereres, E., D.A. Goldhamer, and L.R. Parsons. 2003. Irrigation water management of horticultural crops. HortScience 38:1036-1042.

Fernandez, J.E. and B.J. Bailey. 1994. The influence of fans on environmental conditions in greenhouses. J. Agr. Eng. Res. 58:201-210.

Griesbach, R.J. 2006. Petunia, p. 301-336. In: Anderson, N.O. (ed.). Flower breeding and genetics: Issues, challenges and opportunities for the 21 st century. Springer, Dordrecht, The Netherlands.

Hodges, A.W., C.R. Hall, B.K. Behe, and J.H. Dennis. 2008. Regional analysis of production practices and technology use in the US nursery industry. HortScience 43:1807-1812.

IPCC. 2007. Climate change 2007: Synthesis report. 1 Mar. 2011. <http://www.ipcc.ch/pdf/ assessment-report/ar4/syr/ar4_syr.pdf>

mental conditions affect DWU. DAP and container size were the most important factors affecting DWU, indicating the importance of plant size. DLI was the most important environmental factor and a regression model including main effects of DAP, container size, environmental conditions, and interactions between DAP and the other variables explained $93 \%$ and $91 \%$ of the DWU fluctuations for 'Single Dreams Pink' and 'Prostrate Easy Wave Pink' petunia, respectively.
Jones, H.G. 2004. Irrigation scheduling: Advantages and pitfalls of plant-based methods. J. Exp. Bot. 55:2427-2436.

Jones, H.G. and F. Tardieu. 1998. Modelling water relations of horticultural crops: A review. Sci. Hort. 74:21-46.

Jury, W.A. and H. Vaux. 2005. The role of science in solving the world's emerging water problems. Proc. Natl. Acad. Sci. USA. 102:1571515720. 
Kim, J. and M.W. van Iersel. 2009. Daily water use of abutilon and lantana at various substrate water contents. Southern Nursery Assn. Res. Proc. 54:12-16.

Klassen, S.P., G. Ritchie, J.M. Frantz, D. Pinnock, and B. Bugbee. 2003. Real-time imaging of ground cover: Relationships with radiation capture, canopy photosynthesis and daily growth rate, p. 3-16. In: Digital imaging and spectral techniques: Applications to precision agriculture and crop physiology. ASA special publication no. 66, ASA-CSSA-SSSA, Madison, WI.

Krügera, E., G. Schmidta, and U. Brücknerb. 1999. Scheduling strawberry irrigation based upon tensiometer measurement and a climatic water balance model. Sci. Hort. 81:409-424.

Latimer, J.G. 1991. Container size and shape influence growth and landscape performance of marigold seedlings. HortScience 26:124-126.

Löfkvist, K., R. Larsen, J.E. Englund, and B.W. Alsanius. 2009. Light integral as an indicator of water use in commercial greenhouse nurseries. Acta Agr. Scand. Sect. B-Soil Plant Sci. 59:326334.

Lorenzo, P., E. Medrano, and M.C. SánchezGuerrero. 1998. Greenhouse crop transpiration: An implement to soilless irrigation management. Acta Hort. 458:113-122.

Majsztrik, J.C., A.G. Ristvey, and J.D. Lea-Cox. 2011. Water and nutrient management in the production of container-grown ornamentals. Hort. Rev. 38:253-296.

Medrano, E., P. Lorenzoa, M.C. Sánchez-Guerreroa, and J.I. Montero. 2005. Evaluation and model- ling of greenhouse cucumber-crop transpiration under high and low radiation conditions. Sci. Hort. 105:163-175.

Million, J., T. Yeager, and J. Albano. 2007. Consequences of excessive overhead irrigation on runoff during container production of sweet viburnum. J. Environ. Hort. 25:117-125.

Montero, J.I., A. Antóna, P. Muñoza, and P. Lorenzo. 2001. Transpiration from geranium grown under high temperatures and low humidities in greenhouses. Agr. For. Meteorol. 107:323-332.

Nelson, P.V. 1998. Greenhouse operation and management. 5th ed. Prentice Hall, Upper Saddle River, NJ.

Nemali, K.S. and M.W. van Iersel. 2006. An automated system for controlling drought stress and irrigation in potted plants. Sci. Hort. 110:292297.

Nemali, K.S. and M.W. van Iersel. 2008. Physiological responses to different substrate water contents: Screening for high water-use efficiency in bedding plants. J. Amer. Soc. Hort. Sci. 133: 333-340.

Pieruschka, R., G. Huber, and J.A. Berry. 2010. Control of transpiration by radiation. Proc. Natl. Acad. Sci. USA. 107:13372-13377.

Ray, J.D. and T.R. Sinclair. 1998. The effect of pot size on growth and transpiration of maize and soybean during water deficit stress. J. Exp. Bot. 49:1381-1386.

Rouphael, Y., M. Cardarelli, E. Rea, and G. Colla. 2008. The influence of irrigation system and nutrient solution concentration on potted gera- nium production under various conditions of radiation and temperature. Sci. Hort. 118:328337.

Rouphael, Y. and G. Colla. 2004. Modelling the transpiration of a greenhouse zucchini crop grown under a Mediterranean climate using the Penman-Monteith equation and its simplified version. Aust. J. Agr. Res. 55:931937.

Schuch, U.K. and D.W. Burger. 1997. Water use and crop coefficients of woody ornamentals in containers. J. Amer. Soc. Hort. Sci. 122:727734.

Taiz, L. and E. Zeiger. 2006. Plant physiology. 4th ed. Sinauer Assoc., Sunderland, MA.

van Iersel, M. 1997. Root restriction effects on growth and development of salvia (Salvia splendens). HortScience 32:1186-1190.

van Iersel, M.W. 2003. Short-term temperature change affects the carbon exchange characteristics and growth of four bedding plant species. J. Amer. Soc. Hort. Sci. 128:100106.

van Iersel, M.W., S. Dove, J.-G. Kang, and S.E. Burnett. 2010. Growth and water use of petunia as affected by substrate water content and daily light integral. HortScience 45:277282 .

Warsaw, A.L., R.T. Fernandez, B.M. Cregg, and J.A. Andresen. 2009. Container-grown ornamental plant growth and water runoff nutrient content and volume under four irrigation treatments. HortScience 44:15731580 . 